Aim of the study is to evaluate the results of postoperative radiotherapy of paragangliomas, prognostic factors and causes of treatment failure. Material and methods: Forty-four patients (39 females and 5 males) aged 20 to 74 years were treated for paraganglioma between 1970 and 2010 at the Centre of Oncology in Kraków. Patient survival probability was estimated with the Kaplan-Meier method. Log-rank tests and Cox proportional hazard model were used in univariate and multivariate analysis, respectively. Results: The most common locations of paragangliomas were the following: the ear, carotid body and internal jugular vein bulb. Forty (91\%) out of them were benign and $4-$ malignant. All patients underwent surgery followed by adjuvant radiotherapy. The delivered dose ranged from 50 to $72 \mathrm{~Gy}$, the mean dose was 60 Gy. Five-year overall survival was $84 \%$. Five-year relapse-free survival was $84 \%$, either. The multivariate analysis has shown that the dose in an independent prognostic factor for the overall survival. The univariate analysis has shown significantly higher 5 -year overall survival in patients who received a dose of 60 Gy or higher $-92 \%$ vs. $70 \%$ in patients who received a dose lower than $60 \mathrm{~Gy}$.

Conclusions: Postoperative radiotherapy with doses higher than 60 Gy in patients with paragangliomas is associated with longer overall survival.

Key words: head and neck tumours, paragangliomas, chemodectoma, radiotherapy.

Contemp Oncol (Pozn) 2014; 18 (3): 182-186 DOI: $10.5114 /$ wo.2014.43155

\section{Role of irradiation in combined treatment of head and neck paragangliomas at the Centre of Oncology in Krakow between 1970-2005}

\author{
Magdalena Pęcak, Elżbieta Pluta, Marcin Hetnat, Renata Wróbel-Radecka, \\ Agnieszka Szadurska, Piotr Brandys, Andrzej Kukiełka, Tomasz Dąbrowski, \\ Tomasz Walasek, Jan Skotyszewski
}

Department of Radiotherapy, Maria Skłodowska-Curie Institute - Centre of Oncology, Krakow Branch, Poland

\section{Introduction}

Paragangliomas are rare, non-malignant tumours, originating from neuroectodermal cells. About $5 \%$ of these tumours may show malignant potential. The most common four locations of paraganglioma within the head and neck are the following: the carotid artery bifurcation, the lower ganglion of the vagus nerve, the tympanic cavity (the most common tumour of the middle ear) and the upper bulb of the internal jugular vein [1]. The location of paragangliomas is determined by developmental processes associated with the embrional migration pathway of neural crest cells. Sporadically, paragangliomas were also reported in such locations as larynx, trachea, lung, orbit, nasopharynx, paranasal sinuses or even the omentum. Only in 1-3\% of patients paraganglioma is a hormonally active tumour secreting catecholamines and their metabolites [2-4].

Paragangliomas are slowly growing, hard and painless tumours, with rich vascularity, and are surrounded by a thin capsule. The signs and symptoms depend on tumour location and its growth rate. If the tumour is located in the ear, the most common signs and symptoms are as follows: hypoacusis; tinnitus; otoscopy changes, such as pink colour, bulging and pulsation of the tympanic membrane; tumour in the acoustic meatus, paralysis of the facial, vagus, accessory and sublingual nerves, and headache; and if the tumour is located within the neck, hoarseness, haemoptoe, steadily growing tumour in the upper neck, dyspnoe, tachycardia and skin reddening may be experienced [2, 5].

A breakthrough in the diagnostics of paragangliomas has come along with the development of imaging methods. At present, the diagnosis is based on ultrasound, computed tomography, magnetic resonance imaging and carotid arteriography $[6,7]$.

Biopsy is avoided in the majority of cases due to the risk of bleeding.

Positive family history is found in $10-30 \%$ of patients and is connected with a 2-fold increase of the risk of multifocality. On the other hand, 30\% of the head and neck paragangliomas are of hereditary nature with an autosomal dominant pattern of inheritance with incomplete penetrance. Mutations within genes PGL1, PGL3, PGL4 (responsible for coding of 3 subtypes of succinate dehydrogenase) predispose to paraganglioma occurrence [2-4].

The current local staging classification is the Glasscoc and Jackson classification of the year 1981 or a classification proposed by McCabe and Fletcher [2].

The treatment of paragangliomas depends on the tumour location and stage of the disease. 
The standard of care in patients with early paragangliomas is preoperative tumour embolisation and subsequent surgery. Modern operation techniques allow for surgery procedures associated with increasing probability of cure. Local relapse is observed in 0 to $5.5 \%$ of patients [8]. The risk of cranial nerve (VII, IX, X, XI and XII) injury is $10 \%$ to $40 \%$, and in single paragangliomas of the cervical glomus it rises up to $100 \%[2,3,8-10]$.

Radiotherapy appeared to be an equivalent treatment method, as compared to surgery, due to the risk of haemorrhage during surgery. Obliterative action of ionising radiation against rich vascular network of these tumours as well as the cases where surgery would be associated with serious complications due to the size and location of the tumour are also arguments in favour of radiotherapy $[3,8,11]$.

Radiotherapy is commonly used as single modality treatment in locally advanced paragangliomas or as adjuvant treatment after incomplete resection [2, 8, 12]. There are reports describing the use of preoperative radiotherapy in patients with locally advanced tumour to enable performance of surgery [2].

A newer method is stereotactic radiotherapy which is curative in about $95 \%$ of patients with $8 \%$ of neurological complications, such as cranial nerve neuropathy, transient in nature in the majority of cases $[8,11,13,14]$.

The purpose of this work is to evaluate radiotherapy and other treatment methods in the management of paraganglioma and analysis of prognostic factor and failure pattern.

\section{Material and methods}

Forty-four patients (39 females and 5 males) treated in the Centre of Oncology in Krakow between 1970 and 2005 for a paraganglioma were included in the analysis.

Patients' age ranged from 20 to 74 years. The median age was 44 years.

Forty patients were diagnosed with benign tumours, in 4 cases malignant tumours were found.

Paragangliomas were most commonly located in the middle ear (65\%), carotid body (15\%) and internal jugular vein bulb (9\%). In isolated cases tumours were located

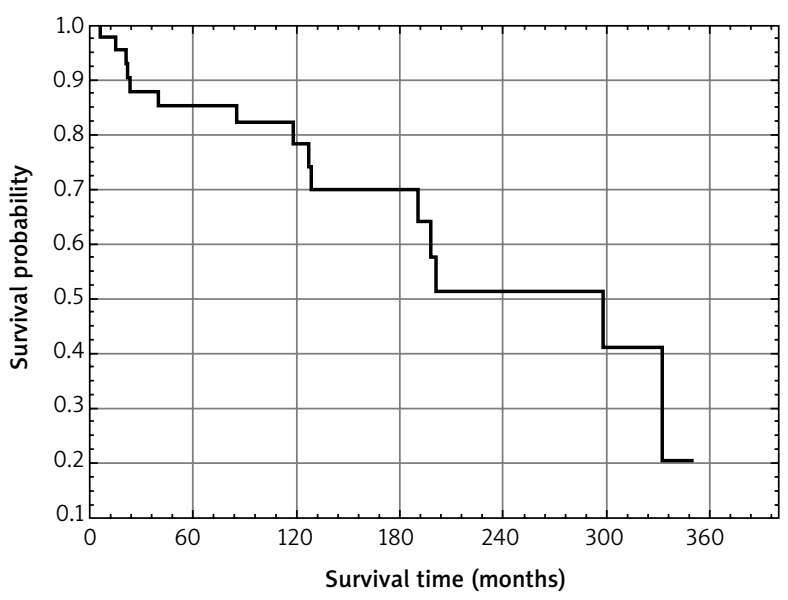

Fig. 1. Overall survival elsewhere (the orbit, the mediastinum, the retroperitoneal space, the base of the skull).

The duration of symptoms ranged from 1 month to 180 months (mean: 49 months) and was longest when paraganglioma was located in the ear. The symptoms varied according to tumour location. The most common symptoms when the tumour was located in the ear were tinnitus, hearing worsening, deafness and discharge from the ear.

One case of family occurrence of the paraganglioma was noted. Surgery was performed in all patients. In $4(9 \%)$ cases this was a complete resection. In 32 (73\%) of patients tumour resection was grossly incomplete, in $8(18 \%)$ of patients - microscopically incomplete.

Postoperative irradiation was performed in all patients.

In 40 patients radiotherapy was indicated because of incomplete resection or tumour malignancy. The interval between the surgery and the start of radiotherapy ranged from 3 to 43 weeks (the median interval was 8 weeks).

All patients were irradiated with use of megavoltage therapy; in 30 patients the cobalt beam was used, 9 patients were irradiated with combined electron - photon beam technique and 5 of them were irradiated with a photon beam. Two oblique beams with wedge filters was the most common technique used - in 42 patients. In 2 patients the technique of two opposite field was used. The [delivered] doses ranged from 18 to $72 \mathrm{~Gy}$, mean dose was 60 Gy in 30 fractions, 2 Gy per fraction.

Overall survival (OS) and disease-free survival (DFS) were the outcome measures in this study. The probability of patients' survival, calculated from the date of surgery to the date of the last follow-up assessment or to the date of patient's death was estimated with the Kaplan-Meier method. Log-rank tests and Cox proportional hazard model were used in univariate and multivariate analysis, respectively.

The following parameters were evaluated in the univariate analysis: age, sex, type of surgery, completeness of resection, time from the surgery to the start of radiotherapy, duration of symptoms, total dose, location and type of the tumour.

$P$-value $<0.05$ was assumed as the threshold of statistical significance.

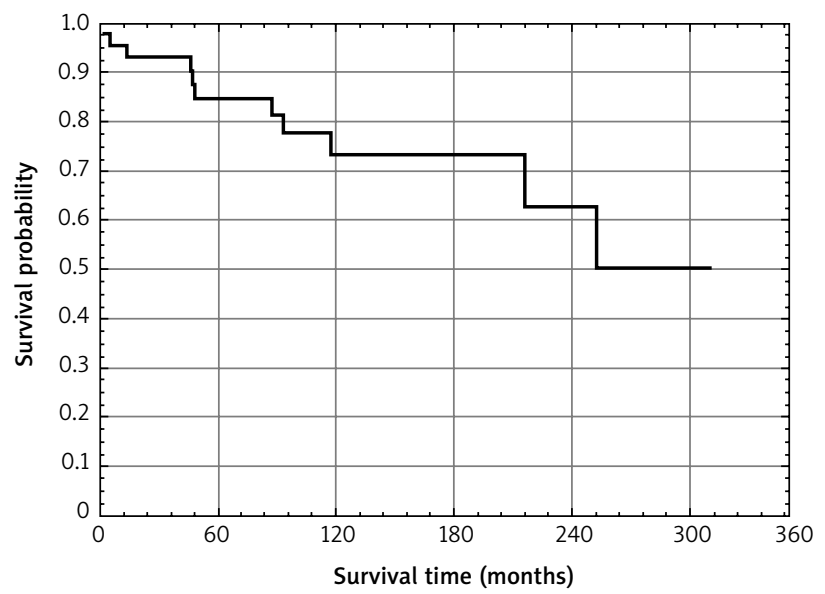

Fig. 2. Disease-free survival 
Analysis of failure patterns and evaluation of early complications were also performed.

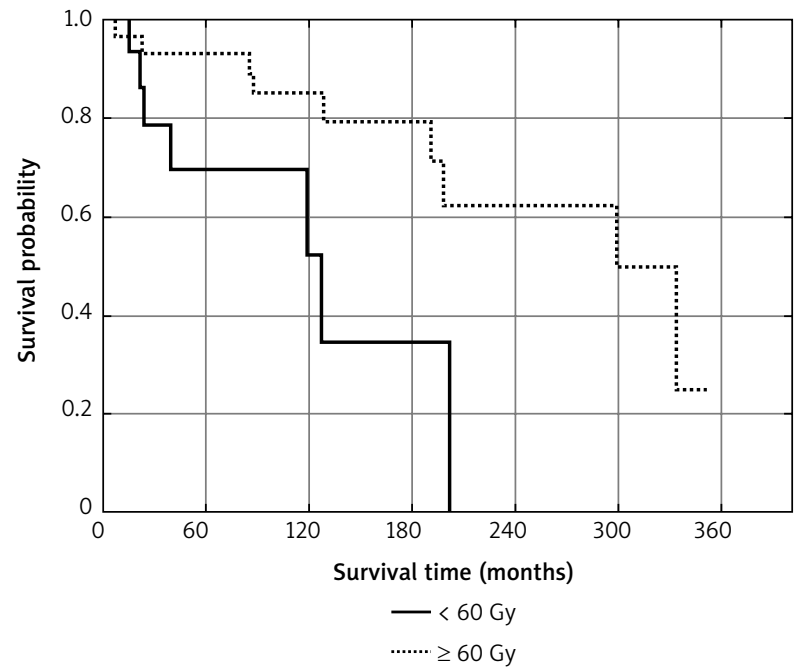

Fig. 3. Disease-free survival by total dose

\section{Results}

The follow-up ranged from 3 to 330 months (the median: 104 months).

Five-year overall survival was 84\%, 5-year disease-free survival was 84\%, which is shown in Figs. 1 and 2.

The univariate analysis has shown significantly better overall survival $(p=0.02)$ in patients who received a dose of 60 Gy or higher (92\%) and in patients who received a dose lower than 60 Gy 5 -year overall survival was $70 \%$ (Fig. 3 and Table 1).

Tumour malignancy significantly affected both overall and relapse-free survival.

Patients who underwent microscopically incomplete surgery had a higher rate of overall survival (100\%), as compared to the patients in whom the surgery was grossly incomplete (84\%), however this difference was not statistically significant. Patients aged 44 years or less had insignificantly ( $p=0.1$ ) better overall survival (95\%) than patients older than 44 years $(74 \%)$.

The other variables included in the univariate analysis had no prognostic value with respect to both overall and disease-free survival.

Table 1. Univariate analysis of prognostic factors (significant bolded)

\begin{tabular}{|c|c|c|c|c|}
\hline Prognostic factors & $\begin{array}{l}\text { Number of } \\
\text { patients }\end{array}$ & $\%$ & 5 year DFS\% & 5 year OS\% \\
\hline Total group & 44 & 100 & 84 & 84 \\
\hline \multicolumn{5}{|l|}{ Gender } \\
\hline female & 39 & 89 & 88 & 82 \\
\hline male & 5 & 11 & 60 & 100 \\
\hline \multicolumn{5}{|l|}{ Age } \\
\hline$>44$ years & 23 & 48 & 84 & 74 \\
\hline$\leq 44$ years & 21 & 52 & 84 & 95 \\
\hline Histological subtype & & & $p<0.0002$ & $p<0.002$ \\
\hline no data & 2 & 5 & 100 & 100 \\
\hline benign & 38 & 86 & 90 & 88 \\
\hline malignant & 4 & 9 & 0 & 50 \\
\hline \multicolumn{5}{|c|}{ Duration of symptoms before treatment } \\
\hline$>36$ months & 22 & 50 & 89 & 90 \\
\hline$\leq 36$ months & & 50 & 79 & 79 \\
\hline \multicolumn{5}{|c|}{ Completeness of operation } \\
\hline RO & 4 & 9 & 50 & 50 \\
\hline R1 & 8 & 18 & 100 & 100 \\
\hline $\mathrm{R} 2$ & 32 & 73 & 84 & 84 \\
\hline \multicolumn{5}{|c|}{$\begin{array}{l}\text { Time between operation and the beginning } \\
\text { of radiotherapy }\end{array}$} \\
\hline of radiotherapy & 20 & 45 & 78 & 80 \\
\hline$\geq 8$ weeks & 24 & 55 & 90 & 90 \\
\hline \multicolumn{3}{|l|}{ Radiation dose } & & $p=0.02$ \\
\hline$<6000$ & 17 & 39 & 71 & 70 \\
\hline$\geq 6000$ & 27 & 61 & 92 & 92 \\
\hline
\end{tabular}


The multivariate analysis has shown that the dose is an independent prognostic factor for the overall survival (Table 2).

Five patients died due to paraganglioma, 1 due to another tumour. There were also 3 deaths due to non-cancer causes and 5 - due to unknown causes. Local progression was found in $8(18 \%)$ patients, metastatic spread of the disease - in $2(5 \%)$ persons. The median time to progression in this group of patients was 48 months. Tumour metastases were found in lungs and bones. No cases of secondary tumours were found.

The treatment was well tolerated. Xerostomy was found in $20 \%$ of patients.

\section{Discussion}

The design of the study is at the same time its limitation: this is a series of cases treated in one centre over a period of 35 years with various treatment techniques. Paragangliomas are rare tumours thus a prospective clinical study to evaluate their treatment is infeasible. Literature data come only from retrospective case series $[8,12$, 15-24].

Another limitation resulting from the length of the analysed period is missing imaging diagnostics [computed tomography (CT), magnetic resonance imaging (MRI)] in the majority of cases. For this reason tumour stage was excluded from analysis.

Patients' characteristics do not differ from those presented in the literature. The highest incidence of paragangliomas is noted between the $4^{\text {th }}$ and the $6^{\text {th }}$ decades of life [2, 4, 21].

The rate of relapse-free survival after conventional adjuvant radiotherapy is about $80-100 \%$ [5, 8, 12, 21, 24]. The results obtained in our Centre of Oncology fall within this range. When using conventionally fractionated radiotherapy, the recommended dose is 45-60 Gy [2, 12, 24]. In our material, in the univariate analysis we have shown a statistically significant effect of the dose on the overall survival. Patients who received a dose of 60 Gy and higher have better disease-free survival and better prognosis. Konefal et al. have demonstrated that the recurrence rate is higher for the doses lower than 41 Gy [17]. Others suggest that the doses above 45 Gy are associated with increased complications without lowering the risk of tumour relapse [24].

Late sequele of radiotherapy are the following: xerostomy, dental caries, hair loss, bone necrosis, middle ear inflammation, brain tissue necrosis, secondary tumours $[2,12,24]$. In our material we have observed xerostomy in $20 \%$ of patients. Konefal et al. report a complication rate of $4 \%$ in patients treated with surgery or curative radiotherapy [17].

Conclusion: our own results as well as the reports published to date show that radiotherapy is an effective method of treatment in patients with paragangliomas.

Precise dynamic radiotherapy techniques introduced on a large scale in the recent years: RT3D (tridimentional conformal radiotherapy), RST (stereotactic radiotherapy), IMRT (intensity modulated radiotherapy), and last but not
Table 2. 5-year OS multivariate analysis of prognostic factors

\begin{tabular}{|cccc} 
& Variable & Relative risk & $p$ \\
\hline OS & $\begin{array}{c}\text { Radiotherapy } \\
\text { dose }\end{array}$ & 0.24 & 0.01 \\
\hline
\end{tabular}

least the progress in patient position verification/correction during irradiation (image guided radiotherapy - IGRT) allow to maintain and possibly improve the level of cure with concurrent maximal protection of the critical organs.

\section{The authors declare no conflict of interest.}

\section{References}

1. Batsakis JG. Paragangliomas of the head and neck. In: Tumors of the head and neck. Clinical and pathological considerations. $2^{\text {nd }}$ ed. Williams \& Wilkins, Baltimore 1976; 280-8.

2. Perez CA, Brady LW. Unusual nonepithelial tumors of the head and neck. In: Principles and practise on radiation oncology. Perez CA (ed.). $4^{\text {th }}$ ed. Lippincott Williams \& Wilkins, New York 2004.

3. Pellitteri PK, Rinaldo A, Myssiorek D, et al. Paragangliomas of the head and neck. Oral Oncol 2004; 40: 563-75.

4. Lee JH, Barich F, Karnell LH, et al. National Cancer Data Base report on malignant paragangliomas of the head and neck. Cancer 2002; 94: 730-7.

5. Luna-Ortiz K, Rascon-Ortiz M, Villavicencio-Valencia V. Carotid body tumors: review of a 20-year experience. Oral Oncol 2005; 41: 56-61.

6. van den Berg R. Imaging and management of head and neck paragangliomas. Eur Radiol 2005; 15: 1310-8.

7. Joynt KE, Moslehi JJ, Baughman KL. Paragangliomas: etiology, presentation, and management. Cardiol Rev 2009; 17: 159-64.

8. Syguła M, Składowski K. Leczenie promieniami przyzwojaków regionu głowy i szyi w materiale Centrum Onkologii - Instytutu w Gliwicach. Otolaryngol Pol 1997.

9. Gottfried ON, Liu JK, Couldwell WT. Comparison of radiosurgery and conventional surgery for the treatment of glomus jugulare tumors. Neurosurg Focus 2004; 17: E4.

10. Li G, Chang S, Adler JR Jr, Lim M. Irradiation of glomus jugulare tumors: a historical perspective. Neurosurg Focus 2007; 23: E13.

11. Jordan JA, Roland PS, McManus C, Weiner RL, Giller CA. Stereotactic radiosurgery for glomus jugulare tumors. Laryngoscope 2000; 110: $35-8$.

12. Lightowlers S, Benedict S, Jefferies SJ, Jena R, Harris F, Burton KE, Burnet NG. Excellent local control of paraganglioma in the head and neck with fractionated radiotherapy. Clin Oncol (R Coll Radiol) 2010; 22: 382-9.

13. Sharma MS, Gupta A, Kale SS, Agrawal D, Mahapatra AK, Sharma BS. Gamma knife radiosurgery for glomus jugulare tumors: therapeutic advantages of minimalism in the scull base. Neurol India 2008; 56: 57-61.

14. Guss ZD, Batra S, Limb CJ, et al. Radiosurgery of glomus jugulare tumors: a meta-analysis. Int J Radiat Oncol Biol Phys 2011; 81: e497-502.

15. Kubiak M, Reszke J, Ziółkowska E. Jugular body tumor lymph nodes metastataes - the case report. Wspolczesna Onkol 2005; 9: 72-74.

16. Bień S, Żyłka S. Nowotwory neurogenne głowy i szyi. Otolaryngologia 2004; 3: 40-4.

17. Konefal JB, Pilepich MV, Spector GJ, Perez CA. Radiation therapy in the treatment of chemodectomas. Laryngoscope 1987; 97: 1331-5.

18. Wang ML, Hussey DH, Doornbos JF, Vigliotti AP, Wen BC. Chemodectoma of temporal bone. A comparison of surgical and radiotherapeutic results. Int J Radiat Oncol Biol Phys 1988; 14: 643-8.

19. Evenson LJ, Mendenhall WM, Parsons JT, Cassisi NJ. Radiotherapy in the management of chemodectomas of the carotid body and glomus vagale. Head Neck 1998; 20: 609-13. 
20. Mendenhall WM, Parsons JT, Stringer SP, Cassisi NJ, Singleton GT, Million RR. Radiotherapy in the management of temporal bone chemodectoma. Skull Base Surg 1995; 5: 83-91.

21. Krych AJ, Foote RL, Brown PD, Garces YI, Link MJ. Long-term results of irradiation for paraganglioma. Int J Radiat Oncol Biol Phys 2006; 65: 1063-6.

22. Papaspyrou K, Mewes T, Rossmann H, et al. Head and neck paragangliomas: report of 175 patients (1989-2010). Head Neck 2012 34: 632-7.

23. Hinerman RW, Amdur RJ, Morris CG, Kirwan J, Mendenhall WM. Definitive radiotherapy in the management of paragangliomas arising in the head and neck: a 35-year experience. Head Neck 2008; 30: 1431-8.

24. Evans JM, Collins M. Clinically diagnosed glomus vagale tumour treated with external beam radiotherapy: a review of the published reports. J Med Imaging Radiat Oncol 2008; 52: 617-21.

\section{Address for correspondence}

Marcin Hetnat MD, PhD

Department of Radiotherapy

Maria Skłodowska-Curie Institute - Centre of Oncology

Krakow Branch

Garncarska 11

31-115 Krakow, Poland

tel. +48505009010

e-mail: marcin.hetnal@gmail.com

Submitted: 5.03 .2013

Accepted: 20.09 .2013 